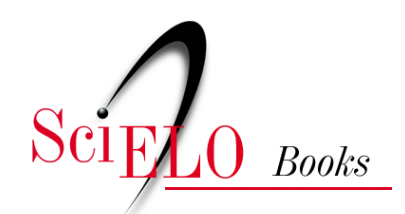

\title{
"O tempo é a minha testemunha" só as pedras estavam aqui, todo o resto é imigrante
}

\author{
Haruf Salmen Espindola \\ Maria Terezinha Bretas Vilarino
}

\section{SciELO Books / SciELO Livros / SciELO Libros}

ESPINDOLA, H.S., and VILARINO, M.T.B. "O tempo é a minha testemunha": só as pedras estavam aqui, todo o resto é imigrante. In: GERHARDT, M., NODARI, E.S., and MORETTO, S.P., eds. História ambiental e migrações: diálogos [online]. São Leopoldo: Oikos; editora UFFS, 2017, pp. 215-235. ISBN: 978-85-64905-68-9. https://doi.org/10.7476/9788564905689.0014.

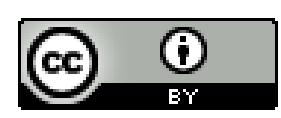

All the contents of this work, except where otherwise noted, is licensed under a Creative Commons Attribution 4.0 International license.

Todo o conteúdo deste trabalho, exceto quando houver ressalva, é publicado sob a licença Creative Commons Atribição $\underline{4.0}$.

Todo el contenido de esta obra, excepto donde se indique lo contrario, está bajo licencia de la licencia $\underline{\text { Creative Commons }}$ Reconocimento 4.0. 


\title{
"O tempo é a minha testemunha": só as pedras estavam aqui, todo o resto é imigrante
}

\author{
Haruf Salmen Espindola \\ Maria Terezinha Bretas Vilarino
}

\begin{abstract}
Promessa de Nambixoré, do povo Maxacali, no sopé do Mikai-kaka. ${ }^{1}$ Não vou odiar o branco como ele odeia nós. Tenho certeza: o branco faz parte da natureza como nós. Grito com todas as forças do meu coração: nunca vou perdoar o mal do branco. Tudo tá gravado no sal da terra, na casca das árvores e na luz das estrelas. O tempo é a minha testemunha. Pode o índio não sobreviver ao mundo "andirri" do branco. Mas o branco também não vai sobreviver ao Mikai-kaka, porque o Mikai-kaka é velho e novo como o tempo (MENDONÇA, 1985, p. 29).
\end{abstract}

\section{Introdução}

A proposta de diálogo entre história ambiental e migrações trouxe à lembrança o Mikai-kaka e a floresta, essa que foi uma migrante que penetrou lentamente na bacia do Rio Doce até se estabelecer completamente, apesar das condições variadas e algumas muito adversas. Mikai-kaka do povo Maxacali são as rochas que emergem nuas de vegetação, presentes em toda a região, cuja geologia é do Arqueano e do Proterozoico, desde a bacia do Rio Doce até a do Jequitinhonha, nos estados de Minas Gerais, Espírito Santo e Bahia. Nambixoré deixa claro que Mikai-kaka estava aqui antes dos brancos, dos índios, dos animais e das plantas, antes de tudo. Quando se olha a paisagem do Rio Doce, se avista o Mikai-kaka por todo lado: o leito rochoso dos rios, os paredões de pedra, os pontões de todas as formas e os lajedos de diferentes extensões, clareiras naturais na vegetação, que no

\footnotetext{
${ }^{1}$ Nambixoré é do povo Maxacali, que habitava diferentes áreas entre os rios Pardo e o Doce (sudeste da Bahia, nordeste de Minas Gerais e norte do Espírito Santo). Maxacali é uma língua do tronco Macro-Jê e se refere a diversos grupos, cujos representantes atuais ocupam a terra indígena no município de Bertópolis, no vale do Mucuri, nordeste de Minas Gerais.
} 
passado distante foram utilizadas pelos Tupi-guarani para instalar raspadeiras e pilões. ${ }^{2}$ Depois que tudo se for, até o homem branco, o "Mikaikaka continuará ali, indestrutível, firme e eterno". Como Nambixoré, podemos afirmar que só restarão as pedras, como antes somente elas estavam aqui, sendo todo o resto imigrante.

Todos somos imigrantes: dos majestosos jacarandá e jequitibá da floresta tropical ao africano capim-colonião, que substituiu a floresta; dos mosquitos transmissores aos patógenos transmitidos (malária, dengue, chikungunya e zika ${ }^{3}$ ); dos remotos Tupi-guarani aos brasileiros atuais. Sedimentos depositados sobre as pedras, chegadas e partidas, na longuíssima duração do tempo, são sinais das muitas ocupações bióticas não humanas e humanas, como uma escrita da natureza. Por quase dois bilhões de anos só existiram as pedras, depois se formaram as condições para que emergisse a vida; longo tempo transcorreu até a formação da floresta tropical e, mais ainda, para que esta colonizasse a Bacia Hidrográfica do Rio Doce. Portanto, a vida se introduziu gradativamente, modificando-se ou extinguindo-se, até que muito recentemente (cerca de $1.000 \mathrm{AP}$ ) se estabeleceram os primeiros assentamentos humanos.

A Mata Atlântica na bacia do Rio Doce apresenta grande variedade na distribuição espacial, com diferentes formações ligadas aos tipos variados de ambientes produzidos pela geologia, relevo e clima, indo das matas perenifólias às caducifólias. A floresta do Rio Doce impressionou diferentes viajantes naturalistas e exploradores, tais como o Príncipe Maximiliano de Wied-Neuwied, Saint-Hilaire, Friedrich Sellow (falecido no Rio Doce, em outubro de 1831), a Princesa Teresa da Baviera, William John Steains, entre outros; além dos estrangeiros que desempenharam funções no Rio Doce, tais como Guido Marlière, comandante geral das Divisões Militares do Rio Doce (DMRD), entre 1824-1929, e Jean-Antoine de Monlevade, fundador da primeira siderúrgica no Vale do Rio Doce, em 1825 (ROCHA, 1971). Como registrou Steains, na sua expedição da foz ao alto Rio Doce, entre junho de 1885 e janeiro de 1886 :

\footnotetext{
${ }^{2}$ Informação presente no estudo arqueológico do EIA/RIMA, elaborado entre dezembro de 1996 e fevereiro de 1998, para o Consórcio da Usina Hidroelétrica de Aimorés, MG.

${ }^{3}$ Segundo dados disponibilizados pela Secretaria Estadual de Saúde de Minas Gerais, em 2017 o Vale do Rio Doce (Leste de Minas Gerais) tem registrado os índices mais elevados de dengue, chikungunya e zika, além do retorno dos surtos de febre amarela.
} 
O grande encanto dessa região do Brasil está nas imensas florestas virgens que cobrem, com grandiosidade sem par, quase a totalidade da área banhada pelo Rio Doce e seus numerosos afluentes. Em ambas as margens do rio, e durante a maior parte do seu curso, essas belas florestas, abundantes em uma centena de espécies da melhor madeira, chegam até à beira d'água, formando uma muralha quase impenetrável da vegetação tropical mais esplendidamente natural que possa ser imaginada (1888, p. 218).

Até o final do século XIX, a presença humana foi reduzida e esparsa, porém na primeira metade do século seguinte intensificou-se a ocupação e devastou-se a floresta (STRAUCH, 1955). Os vestígios mais antigos de assentamentos humanos, conforme indicações arqueológicas, são de "povos indígenas relacionados à cultura Tupi-guarani”, entre 900 e 700 AP (BAETA; MATTOS, 2007, p. 43). Em busca da Serra das Esmeraldas, nos séculos XVI e XVII, os portugueses tiveram contato com povos nômades caçadores e coletores nos rios Doce e Jequitinhonha. Esses nômades, pertenciam a quatro diferentes línguas do tronco Macro-Jê (Botocudo, Maxacali, Puri e Pataxó), distribuíam-se pela área que corresponde atualmente ao norte do Rio de Janeiro, leste de Minas Gerais, norte do Espírito Santo e centro-sul da Bahia.

No século XVIII, com o estabelecimento da mineração na bacia do Rio Doce (Mariana, Peçanha, Antônio Dias, São José da Lagoa, etc.), as diversas expedições prospectivas de riquezas minerais, e com o progressivo avanço da ocupação das terras florestais, criou-se uma zona de contato e conflitos com os povos nativos, particularmente com o Botocudo. No começo do século XIX a Coroa Portuguesa declarou guerra ofensiva aos Botocudo (1808) e ordenou a ocupação militar dos sertões do Rio Doce e do Jequitinhonha. Quartéis foram colocados em pontos estratégicos para o controle territorial, incluindo as margens do Rio Doce, frequentadas, pelo lado esquerdo, por tribos da nação Naknanuk e, pelo direito pelas da nação Nakrehé. ${ }^{4}$ Como o povo Botocudo não conhecia a navegação, o rio era uma barreira que impedia o contato entre as tribos dessas nações. Eles não se fixavam e antes das estações das chuvas se retiravam para as terras altas. A ausência de povoamento às margens do Rio Doce foi o principal óbice para a navegação fluvial regular, objetivo maior da guerra ofensiva (ESPINDOLA, 2005).

\footnotetext{
${ }^{4}$ O Rio Doce é o Watu (grande rio) do povo Botocudo (Krenak), que mantém com ele uma relação espiritual.
} 
No século XIX, a Coroa Portuguesa e, depois, o Império do Brasil usaram de vários artifícios para fomentar a fixação de povoamento às margens do Rio Doce: perdão de dívidas e isenção de impostos para a colonização espontânea; manutenção das concessões de sesmarias (mesmo depois da suspensão desse estatuto jurídico pelo Príncipe Dom Pedro, em julho de $1822^{5}$ ); envio de degredados; concessão de privilégios e isenções fiscais para companhias de navegação e colonização; envio de missionários para catequese e civilização, entre outros. A história contraria a geografia do grande rio. Como observou Strauch $(1955$, p. 4), a forma e a extensão da bacia do Rio Doce formam um caminho natural para penetração no planalto, estabelecimento da colonização e garantia da comunicação, transporte e integração. Entretanto, a ocupação concentrou-se nas terras altas e, à medida que se descia para as margens do grande rio, o povoamento permaneceu restrito aos estabelecimentos militares e aldeamentos missionários.

A principal causa (ou das mais relevantes) da não fixação humana no Vale do Rio Doce, propriamente dito, pode ser encontrada em Saint-Hilaire (1974, p. 41 e 78), quando da sua viagem ao Espírito Santo e Rio Doce, em 1818. Ele estava empolgado com a viagem ao Rio Doce e, ao mesmo tempo, com medo: "não posso pensar nessa viagem sem estremecer". O próprio governador da capitania traçou com "as cores mais sombrias a região deserta" e, principalmente o preveniu contra a insalubridade: "O Rio Doce é um inferno". Apesar das ideias otimistas sobre o potencial econômico dos sertões do Rio Doce, o naturalista se mostrou pessimista depois que ele próprio experimentou as dificuldades e viu toda sua comitiva tomada pelas febres intermitentes (malária). As condições adversas também são apresentadas pelos frades capuchinhos italianos do aldeamento de Itambacuri (MG), enviados pelo governo do Império, em 1873, para a catequese e civilização dos índios das bacias do Rio Doce, São Mateus e Mucuri. Eles mencionam os perigos das derrubadas e os sacrifícios do trabalho braçal, mas os piores flagelos eram os mosquitos, as febres e a fome. A irregularida-

\footnotetext{
${ }^{5}$ Resolução N. 76 - Reino - de Consulta da Mesa do Desembargo do Paço, de 17 de julho de 1822. Resolução: Fique o suplicante na posse das terras que tem cultivado e suspenderam-se todas as sesmarias futuras até a convocação da Assembleia Geral, Constituinte e Legislativa. Com o rubrica de S. ${ }^{a}$ Real o Príncipe Regente. José Bonifácio de Andrada e Silva. Fonte: Coletânea de Legislação e Jurisprudência Agrária e Correlata organizada por Joaquim Modesto Pinto Júnior e Valdez Farias (Brasília: MDA, 2007, p. 44).
} 
de das chuvas trazia a fome: onde eram abundantes, impediam as queimadas e, sem plantação, provocam a escassez geral de víveres; onde faltava chuva, nada crescia, como ocorria em certos anos, às margens do Rio Doce (PALAZZOLO, 1952).

Apesar dos esforços oficiais, vários fatores mantiveram a bacia do Rio Doce despovoada, exceto na sua porção oeste, onde se localizaram as cidades do período aurífero. No último quartel do século XIX, essa zona aparecia nas cartas geográficas da Província de Minas Gerais como "matas pouco conhecidas e habitadas por indígenas". Os elementos apresentados até aqui já indicam a relevância do assunto para o diálogo entre história ambiental e migrações. Em seguida abordaremos os choques entre assentamentos humanos e ecossistema no Vale do Rio Doce; e de como essa relação se desequilibra com a entrada dos interesses capitalistas, no século XX.

\section{Confederados americanos no Rio Doce: floresta, mosquitos, chuvas e imigrantes}

Na segunda metade do século XIX, o esforço para colonizar as terras ribeirinhas do Rio Doce foi entregue às companhias de imigração, organizadas para esse fim. Merece destaque a Colônia de Francilvânia (1857-1860), instalada às margens do Rio Doce, onde hoje se localiza a cidade de Colatina, no Espírito Santo. ${ }^{6}$ Foi uma iniciativa de Nicolau Rodrigues dos Santos França e Leite ${ }^{7}$, que obteve vasta quantidade de terras para assentar 2.000 imigrantes portugueses, franceses e alemães, em cinco anos: "Os governantes alegraram-se em ver França e Leite explorar o Rio Doce por conta própria" (FISCHER, 2008, p. 63-64). O fracasso da colônia foi atribuído ao Botocudo (KODAMA, 2008, p. 414). Em 1885, Steains (1888b, p. 6667), não encontrou "o mais leve sinal de que essa tentativa de colonização tenha sido feita". Ele informa o motivo corrente do fracasso: "o assassinato, por um grupo de botocudos, do jovem Avelino (parente próximo do Dr.

\footnotetext{
${ }^{6} \mathrm{~A}$ área da antiga colônia, na última década do século XIX, foi ocupada por imigrantes que desceram das serras capixabas, dando origem ao município de Colatina.

${ }^{7}$ O paraibano Nicolau França e Leite (1803-1867) era companheiro de Teófilo Otoni (18071869) e com ele participou do jornal "O Philantropo", órgão de difusão da Sociedade Contra o Tráfico de Africanos e Promotora da Colonização, e Civilização dos Indígenas, fundada em 2 de setembro de 1850 . Os dois empreenderam projetos pessoais de colonização que tiveram vida breve: Teófilo Otoni dirigiu a Companhia de Comércio e Navegação do Mucuri (1847-1863).
} 
França e Leite)". Nos relatos recolhidos por Steains se encontra a recorrente representação dos Botocudo como "canibais": depois de porem fogo nas cabanas "que compunham a colônia", os Botocudo teriam dividido "o corpo do pobre Avelino em postas, assaram-no e, depois de descansar um pouco para facilitar a digestão, partiram novamente para seus redutos". Essa representação do Botocudo como obstáculo era forte:

A divisão binária entre a terra civilizada e a terra selvagem obteve sua expressão geográfica no curso do Rio Doce. Não parecia ser um lugar adequado para estabelecer "núcleos de radiação" e em 1861 José Fernandes da Costa Pereira Junior admitiu que a morte de Avelino mostrou que os sertões do vale do Doce "só lentamente irão atraindo a população". Em 1876 Alves concluiu que de Francilvânia "não resta o mínimo indício".

Durante a segunda metade do século XIX, o Rio Doce tornou-se uma frente simbólica importante na imaginação da elite do Espírito Santo. [...] Francilvânia é um de vários exemplos. Seu fracasso estabilizou ainda mais a geografia binária imaginada. [...] ...pensava-se, a estrada de ferro faria com que desaparecesse o irritante "outro" - o índio Botocudo (FISCHER, 2008, p. 66).

A experiência da imigração norte-americana originada dos Estados Confederados, derrotados na Guerra de Secessão, em 1865, indica claramente serem outros os motivos que impediam a fixação de assentamentos humanos na floresta tropical, às margens do Rio Doce. Segundo Rocha (1971), dois americanos estiveram no Rio Doce, em 1870, pretendendo estabelecer uma companhia de navegação com linha direta para os EUA. O autor capixaba Manoel Ferreira, em sua História e Flagrantes de Baixo Guan$d u$, menciona a presença desses americanos. ${ }^{9} \mathrm{O}$ geólogo Charles Frederick Hartt (1941) encontrou no Rio Doce esses colonos recém-chegados. O estabelecimento desses confederados no Rio Doce fundamentou-se na promessa de serem as terras baratas e as mais férteis do Brasil, além de poderem comprar escravos.

As dificuldades para a fixação do povoamento às margens do grande rio podem ser encontradas no manuscrito de 1874, "Our Life in Brazil: 1867-1870", de Julia Louisa Keyes, no qual ela descreve as experiências de

\footnotetext{
${ }^{8}$ Estudos recentes têm desconstruído essa versão, com inúmeras provas de que os Botocudos não eram antropófagos nem foram entraves para a ocupação luso-brasileira das terras do Rio Doce (ESPINDOLA, 2005).

${ }^{9}$ Em Baixo Guandu viveu o norte-americano Thomaz, chefe de grande família, fixou-se no lado direito da embocadura do rio (Guandu)... Da prole, lembramo-nos de Laurindo, Franklin, Jonson, Clóvis, David; um Cútis, um Joãozinho. Havia, ainda, mais de uma filha (FERREIRA, 1985).
} 
sua família e dos outros imigrantes, durante os três anos passados no Rio Doce. Outras fontes importantes são as correspondências desses imigrantes e o livro da descendente Judith Jones, que tem o sugestivo título de "Soldado descansa! Uma epopéia norte-americana sob os céus do Brasil" (1967).

Diferente da Colônia de Francilvânia, os imigrantes confederados não eram camponeses pobres em busca de terra ou trabalho. "Não se tratava de um movimento de camponeses repelidos da terra ou de um proletariado miserável em busca de uma pátria em que ganhasse o pão" (RIOS, 1949, p. 944). Eram médicos, oficiais da marinha e do exército confederado, sacerdotes etc., que possuíam recursos financeiros e tinham em comum o descontentamento com o fim da escravidão e com a derrota para a União. ${ }^{10}$ Observadores foram despachados para o Brasil, com os objetivos de verificar as alternativas de localização e informar sobre os aspectos socioeconômicos, políticos e ambientais. Os relatórios produzidos, com raras exceções, foram favoráveis, chegando alguns a serem ufanistas. Esse foi o caso do ex-deputado do Alabama e oficial confederado Charles Grandison Gunter, que depois de visitar diferentes lugares, em 1865, decidiu estabelecer uma colônia no baixo Rio Doce, próximo a atual cidade de Linhares, no Espírito Santo. ${ }^{11}$

Gunter conseguiu do governo cerca de 155.400 hectares, além de várias promessas de auxílio. Com um ano instalado no Rio Doce, escreveu aos amigos: "Venha para cá e compre terras... melhor que qualquer nos Estados Unidos, mesmo nas zonas mais férteis do Alabama"; para outro recomenda trazer toda a família, pois com a ajuda dos filhos seria independente em um ano; recomendava: "traga ferramentas consigo, todas que puder, porque as suas são melhores do que as que podem ser adquiridas aqui"; "traga todas as qualidades de sementes"; "traga outras famílias iguais à sua, posso garantir-lhes casa e muita terra abençoada pela Providência,

\footnotetext{
${ }^{10}$ A maioria trouxe consigo esposa e filhos, alguns ainda bebês. Dos confederados que deixaram os Estados Unidos, logo após a guerra, segundo Richard Burton, 2.070 vieram para o Brasil, dos quais 400 para o Rio Doce (RIOS, 1949, p. 947)

${ }^{11}$ Gunter nasceu na Carolina do Norte, em 1806, mas estabeleceu-se no Alabama, onde fez fortuna como fazendeiro. Depois da Guerra da Secessão migrou para o Brasil, onde faleceu em 1883. (Biography: Charles Grandison Gunter born February 28, 1806 - photographs. By Donna R Causey on February 28, 2013. Publicado no site Alabama Pioneers. Disponível em: $<\mathrm{http}$ ://alabamapioneers.com/biography-charles-grandison-gunter-born-1806-with-photographs/>. Acesso em: 2 maio 2017.
} 
mais do que qualquer outra que já vi". O ufanismo de Gunter chegou ao exagero: "Quase perdoei nossos inimigos, só pelo fato de ter sido forçado a vir para este país melhor". A primeira leva de sulistas desembarcou no Rio Doce, em 1867, de onde seguiriam para a Colônia Gunter.

Soubemos que para alcançar nosso destino deveríamos navegar o Rio Doce acima em canoas, após desembarcarmos do vapor sobre a barra. [...] A grande questão das canoas, nas quais realizaríamos a viagem rio acima, foi o assunto que nos deixou absortos. Os homens se reuniram, fazendo planos, e as senhoras consideravam como suportariam a viagem desse modo insólito. Um grupo de cavalheiros tomou uma rota terrestre, a maioria a pé, em companhia do Coronel Gunter. O Sr. Roussell tinha certo número de escravos que o acompanhavam. Um grupo se foi, o restante estava preparado e esperando avidamente. [...] $\mathrm{Na}$ vida pioneira o verdadeiro caráter se mostra e uma grande variedade de características se evidencia sob nossa observação (KEYES, 2013, p. 83-85).

Os imigrantes vivenciaram dois momentos distintos: o primeiro marcado pelo otimismo de quem se sentia numa "terra prometida"; o segundo de desespero, de quem se sentia transportado para o "inferno". As correspondências pessoais reproduzidas por Judith Jones (1967) e o diário de Keyes (2013) permitem compreender as situações enfrentadas e as razões do fracasso. No primeiro momento a paisagem tropical do "grande rio" (como Gunter nomeava o Rio Doce, do mesmo modo que faziam os Botocudos, ao chamá-lo de Watu) aparece como uma natureza idílica, na qual os lugares são sempre "muito bonitos", as terras "muito férteis" e a vida maravilhosa. Josephine Foster, em um trecho de sua carta publicada no New Orleans Times, em 24 de abril de 1868, diz: "a dez passos atrás da casa começa a floresta interminável que dizem ter muitos animais ferozes, mesmo assim, mamãe e eu e as crianças temos dormido sozinhas muitas noites, sem portas ou janelas e nunca dormimos tão bem em nossas vidas". Keyes conta sobre as festas que realizavam no final do dia de trabalho: "A primeira festa foi em nossa casa":

Nós tínhamos representantes de quaisquer Estados do Sul à nossa volta. Três jovens rapazes no cômodo eram de Montgomery, Alabama. Dois da Louisiana, um do Texas, um da Flórida, um da Virgínia, um do Tennessee. [...] Entre nós havia colonos da Geórgia e das Carolinas, alguns de diversas partes do país que nós deixamos, e um interesse comum fazia-nos sentir próximos uns dos outros (2013, p. 104-105).

Nesses dias felizes, um momento de susto foi o aparecimento do Botocudo. Keyes (2013, p. 101-102) descreve o medo que tomou conta da vila 
e de como os habitantes se trancaram em suas casas. "Americanos agitados. Alguns trêmulos. Índios Booga (sic) estavam na vila". Eram as "coisas mais feias que se pode imaginar" e todos se entregaram "ao desânimo, em seu grau mais baixo". Ficaram paralisados de pânico, "até que uma voz reconfortante, que conhecíamos bem, pediu para entrar". Era o Dr. Dunn e todos o saudaram: os medos foram dissipados. A preocupação era se os índios lhes fariam mal, mas Dr. Dunn foi firme: "Nenhum nesse mundo. [...] Uma arma americana poderia dispersar a raça inteira. Acalmem-se". A situação se normalizou. "A casa estava alegre mais uma vez. As janelas e as portas escancaradas, pois os índios passaram pela cidade e acamparam nas cercanias da vila". Como se verá a seguir, o verdadeiro perigo era outro.

Em 26 de outubro de 1867, Keyes (2013, p. 162) registrou em seu diário: "Não gostamos da ideia da doença em nossa colônia, mas ouvimos que um bom número está tendo febres". Segundo Judith Jones (1967, p. 108-109), depois de um primeiro momento de esperanças em relação ao futuro, com poucas exceções, as famílias começaram a deixar o Rio Doce. As dificuldades surgiram na sequência da alteração do meio para o estabelecimento da colônia: clareiras abertas, queimadas e início das plantações. A suposta terra da promissão acabou expulsando-os: as nuvens de mosquitos; as invasões de formigas, as febres e o clima. Os mesmos problemas das febres e da irregularidade do clima, destacados pelos frades capuchinhos de Itambacuri, estão no relato de Keyes: depois de um ano de muita chuva, que tudo estragou, veio "uma grande seca... matou as verduras, as roças, trouxe a maleita [malária]... não sobrando ninguém que não tivesse sido acometido". ${ }^{12}$ Pelo diário de Keyes, descobre-se que os problemas começaram seis meses depois de estabelecida a colônia:

Quão mudada estava nossa vida na lagoa em relação à sociabilidade agradável dos primeiros seis meses, quando saúde e esperança tornavam cada dia delicioso. Os cavalheiros, que constantemente tinham tremores, estavam em desalento e desanimados. Os escravos nunca estavam aptos, mais da metade por vez, ao trabalho, e aqueles que começaram a desbastar e a plantar com tanto empenho agora estavam desencorajados. As plantações foram destruídas pela seca incomum. Nada parecia ter futuro em nossa bela colônia nova (2013, p. 194).

\footnotetext{
${ }^{12}$ Evidente que são muitos os fatores que explicam o fracasso da maioria das colônias formadas com imigrantes americanos confederados. Não deixa de ser relevante a dispersão dos núcleos de colonização por todo o vasto território brasileiro, como observou Artur Rios (1949, p. 951), para quem esse foi um dos principais fatores para o malogro, exceto no caso de Americana, no estado de São Paulo.
} 
Keyes anotou no diário, no dia 12 de novembro de 1867: "Mais chuva. As crianças ainda estão tendo tremores, mas não parecem muito doentes. Assim que a febre se vai, elas vão brincar", porém a situação se agravou: "O senhor Spencer estava próximo da morte e muito poucos americanos estavam aptos a remar até mesmo uma canoa pequena, pois quase todos estavam doentes com tremores e febres" (KEYES, 2013, p. 190). A Colônia do Rio Doce foi desfeita, ficando poucas famílias em definitivo, como a do Coronel Gunter, que faleceu em Linhares, em $1883 .{ }^{13}$

\section{Floresta e migração interna}

O fracasso da imigração confederada no Rio Doce está relacionado diretamente com a história ambiental e, ao mesmo tempo, confirma os motivos anteriores e posteriores para o não assentamento humano às margens do grande rio. Em um estudo sobre o médio Rio Doce, de 1904, a área é apresentada como um vazio demográfico, coberta de "luxuriante floresta". O estudo estimou a população em 255 mil habitantes concentrada nas terras altas, porém constatou a existência de uma frente de ocupação demográfica se movimentando no sentido de ocupar o interior da bacia do Rio Doce, tendo no café a força motriz da migração (ROSA, 1976). As terras florestais atraíam os posseiros que buscavam os terrenos devolutos (terras públicas): esses migrantes buscavam a "Mata" do Rio Doce.

Entretanto, havia dificuldades diversas a serem enfrentadas. Em 1911, o engenheiro Álvaro da Silveira (1922, p. 496-497), no estudo para fundamentar Minas Gerais nas disputas por limites com o Espírito Santo, além de referir-se às áreas "pestíferas", dominadas pela malária, destaca a irregularidade do clima e a fragilidade hídrica. Sua atenção foi atraída pelos rios e córregos secos, no interior da mais densa floresta. Eram os meses de setembro e outubro de 1911, ano em que a estiagem foi prolongada. Nesse cenário adverso, a construção da ferrovia, iniciada em 1903 (Vitória, ES) e concluída em 1942 (Itabira, MG), produziu a transformação da paisagem e

\footnotetext{
${ }^{13}$ Seu filho Basil Manley foi nomeado representante consular em Vitória, em 1889, teve ações de ferrovia e ganhou fortuna (JONES, 1967, p. 109-110). Em 1971, o neto do filho de Gunter que foi estudar nos EUA, escreveu, sobre o tio Basil Manley: “... por anos ele enviou dinheiro a minha mãe, grandes quantias no início, mas que foram gradualmente diminuindo, até que ele escreveu que a plantação não estava pagando nada e que mamãe teria que lhe enviar dinheiro para os impostos. Isso foi talvez no ano de 1900" (NEELEMAN, 2016, p. 135).
} 
promoveu o primeiro movimento de adensamento humano do Vale do Rio Doce, propriamente dito. ${ }^{14}$ Como deixa claro Demerval Pimenta (1974), a ocupação efetiva do Vale do Rio Doce foi um acontecimento do século XX, cujo fator de penetração foi a Estrada de Ferro Vitória-Minas (EFVM).

Com efeito, no último quartel do século XIX e nas três primeiras décadas do XX, uma frente demográfica de ocupação avançou progressivamente. ${ }^{15} \mathrm{Na}$ porção meridional da bacia do Rio Doce, esse avanço se liga à expansão cafeeira, a partir da Zona da Mata; na porção setentrional esse movimento foi mais lento, com uma frente cafeeira e outra de pecuária bovina, porém ocupando o Noroeste, com limite no Rio Suaçuí Grande. Na porção setentrional nordeste, tendo contigua a bacia do Rio São Mateus, o movimento ainda foi mais tarde (década de 1930), com base no café. A EFVM atraiu a frente demográfica para as margens do Rio Doce tanto lavradores de subsistência e pequenos cafeicultores quanto alguns criadores de gado provenientes do Jequitinhonha e Norte de Minas. Como registrou Salm de Miranda (1949, p. 53-54), os migrantes eram posseiros (que os agentes do governo tratavam por invasores) e formavam dois grupos bem distintos, sendo pretos ou "roxos" os nacionais e "brancos" os alemães ou italianos (ou seus descendentes), que tinham decido das serras do Espírito Santo. Na década de 1930 essa frente se estabeleceu no Vale do Rio Doce, propriamente dito, e avançou na direção das terras ao norte, penetrando a bacia do Rio São Mateus (WAIBEL, 1955).

A construção da ferrovia junto às margens do Rio Doce foi marcada por grande dificuldade para se conseguir trabalhadores ou para repor os que morriam ou ficavam "imprestáveis" por causa da insalubridade e, particularmente, pela malária. Como medida saneadora e para combater a multiplicação dos casos de trabalhadores doentes, as matas eram derruba-

\footnotetext{
${ }^{14}$ A história da EFVM tem três fases diferentes: 1) período de 1901-1910, no qual o controle era dos engenheiros João Teixeira Soares e Pedro Nolasco Pereira da Cunha, fundadores da empresa; 2) período de 1910-1942, no qual o controle foi da Itabira Iron Ore Company, cujos acionistas eram representados por Percival Farquhar; 3) a partir de 1942 o controle é da Companhia Vale do Rio Doce. A ferrovia avançou rápido durante a primeira fase, chegando a atual cidade de Governador Valadares, em 15 de agosto de 1910. Nesse ano, a ferrovia passou ao controle da Itabira Iron e o traçado foi mudado de Diamantina para Itabira e o objetivo passou a ser o transporte de minério de ferro, objetivo que só se efetivará com a criação da Companhia Vale do Rio Doce, em 1942.

${ }^{15} \mathrm{O}$ conceito de frente demográfica de ocupação e o de frente pioneira, como diferentes tempos e produtores de espacialidades distintas são de José de Souza Martins (1996).
} 
das em grande escala e queimadas, como consta na justificativa da diretoria da Companhia Estrada de Ferro Vitória a Minas (EFVM) para a Assembleia Geral Ordinária, de 12 de setembro de 1908. Diz o presidente da companhia, Dr. Teixeira Soares:

A camada enorme de húmus, que garante uma fertilidade quasi que inexgotável as margens do Rio Doce, encerra o gérmen de febres de máocaracter, que - desaparecem quando se vão descortinando os terrenos por meio das derribadas em larga escala. [...] as derribadas que têm sido feitas para passagem da estrada e o descortinamento gradual dos terrenos estão já produzindo seus benéficos effeitos sobre as condições sanitárias (Relatório da Diretoria da EFVM apud ROSA, 1976, p. 119-120).

Aqui, além de observamos a permanência de uma concepção telúri$\mathrm{ca}^{16}$ da origem das doenças que eram entrave à ocupação, com a afirmação de que o terreno "encerra o germe de febres de mau caráter", podemos perceber que a derrubada da mata era tida como uma medida saneadora que produziria o efeito higienizador. ${ }^{17}$ Se o paludismo (malária) funcionou como obstáculo ao povoamento e à exploração, combater a doença se transformou em luta contra a floresta. As clareiras abertas na floresta pela EFVM, os acampamentos dos trabalhadores e as demandas para abastecê-los fomentaram o surgimento de povoações e, desta forma, multiplicavam-se as frentes de exploração dos recursos florestais e de desmatamento para introduzir a agricultura ou pecuária. As estações ferroviárias se constituíram em centros de adensamento demográfico. Na memória do engenheiro Ceciliano de Almeida, que trabalhou na construção da ferrovia, entre 1905 e 1908, se podem constatar as mudanças provocadas pela chegada dos trilhos, que segundo ele, colocavam as poucas aldeias apáticas no rumo do progresso:

[...] a ponta dos trilhos avizinha-se de Colatina. Breve, o estardalhaço das locomotivas [...] anunciando a penetração, Rio Doce acima, nas florestas virgens paludosas ${ }^{18}$. Profundas alterações sofrerá a região [...] foram dominadas as matas desconhecidas. $\mathrm{Na}$ área por elas ocupada, apareceram os

\footnotetext{
${ }^{16}$ De acordo com a "doutrina telúrica", as doenças eram produzidas por emanações malignas provenientes do solo. A terra era a produtora do mal, da doença.

17 "Campanhas contra endemias rurais, e contra a malária em particular, são elementos constitutivos da saúde pública no Brasil. Desde o início do século XX, inúmeras ações que incluíam investigação, tratamento e profilaxia do impaludismo foram executadas pelo governo federal e por alguns estados da federação. Cf. HOCHMAN, G.; MELLO, M. T. B.; SANTOS, P. R. E. A malária em foto: imagens de campanhas e ações no Brasil da primeira metade do século XX. Hist. Cienc. Saude-Manguinhos, Rio de Janeiro, v. 9, supl. p. 233-273, 2002.

${ }^{18}$ Paludosas se refere à presença do paludismo/malária.
} 
agricultores, tiradores de madeira, exploradores de pedras coradas, pecuaristas e negociantes (1978, p. 6).

Com incentivo da EFVM, a cultura do café e a extração da madeira se tornaram as principais atividades econômicas e geradoras das receitas da ferrovia. Na década de 1920, o transporte de passageiros assumiu a segunda posição na geração de receitas, atrás do café, confirmando o crescente adensamento demográfico ao longo da ferrovia e regiões vizinhas (ROSA, 1976, p. 165). ${ }^{19}$ No início da década de 1940 esse adensamento passou a ser impulsionado também pela produção de carvão vegetal, com objetivo de atender as siderúrgicas que se implantavam com apoio do governo de Minas Gerais e as dezenas de fábricas de ferro gusa que se espalharam pela região. Nessa década, o Vale do Rio Doce já apresentava um quadro de desmatamento crescente, em função da combinação da frente de ocupação aberta pela EFVM e do início da indústria do Carvão. ${ }^{20}$ Cesar Pinto (1944, p. 213), biólogo do Instituto Oswaldo Cruz e chefe do Serviço de Doenças Parasitárias do Departamento Nacional de Estradas de Rodagem (DNER), descreve a região que encontrou em 1942: "outrora coberta por densas matas virgens em grande parte destruídas hoje pelo homem, para extração de lenha destinada ao fabrico de carvão, consumido pela indústria do ferro". ${ }^{21}$

Entretanto, a opinião pública nacional acreditava e continuou por muito tempo a imaginar, que no Rio Doce existia uma opulenta floresta, como se depreende pelas palavras do grande escritor Câmara Cascudo, escritas em 1956: "lugar para explorar, locar e construir na mata margeante do Rio Doce, onde há árvores contemporâneas do Gênesis". ${ }^{22} \mathrm{Na}$ verdade,

${ }^{19}$ ROSA, Léa Brígida Rocha de Alvarenga. Companhia Estrada de Ferro de Vitória a Minas. 1890-1940.

${ }^{20} \mathrm{O}$ engenheiro alemão Guilherme Giesbrecht, responsável pela abertura da primeira estrada de rodagem da região (Figueira a Itambacuri), anotou em seu relatório que os moradores da vila de Figueira (Governador Valadares) foram chamados para um evento na praça do coreto, em 1936, no qual ouviram do representante da Companhia Siderúrgica Belgo-Mineira a notícia de que a empresa iniciaria as atividades da usina de João Monlevade e, por isso, precisaria comprar muito carvão vegetal. Disse que a empresa iria apoiar e que a nova atividade traria o progresso, além de contribuir para sanear a região, infestada de malária (SIMAN, 1988, p. 99-100).

${ }^{21}$ O relatório escrito pelo Dr. Cesar Pinto, em 1944, contém o diagnóstico e as ações executadas de combate às doenças que atingiam os rodoviários que construíam a rodovia Rio-Bahia e a população próxima, nos anos de 1942 e 1943. O Diagnóstico foi sobre a área do Vale do Rio Doce, ao longo do trecho da rodovia, entre o município de Governador Valadares e o de Itambacuri (PINTO, 1944).

22 Essas palavras de Câmara Cascudo foram escritas em 1956, ao prefaciar as memórias do engenheiro Ceciliano Abel de Almeida (1978, p. XII). 
a floresta ficou comprometida em seu frágil equilíbrio, quando se multiplicaram as clareiras abertas e se repetiram as queimadas utilizadas pelos agricultores, antes do período das chuvas e da semeadura. Os patógenos e seus transmissores, no entanto, continuavam presentes, dificultando as obras de infraestrutura rodoferroviária e hidroelétrica, limitando o avanço da frente pioneira e, principalmente, prejudicando os grandes investimentos de capitais privados e estatais. Conforme Cesar Pinto (1944, p. 267), os centros urbanos não apresentavam a mínima infraestrutura de abastecimento de água e luz elétrica; não tinham condições sanitárias; estavam tomadas de criadouros de larvas de mosquitos transmissores de malária, cujos surtos eram frequentes.

O enfrentamento desse quadro adverso, a partir de 1942, foi motivado pela combinação dos interesses acima e pelas injunções internacionais ligadas aos interesses aliados na Segunda Grande Guerra. O saneamento e controle dos patógenos foram ações estratégicas imprescindíveis para a implantação dos dois importantes sistemas territoriais: o siderúrgico e o minerador. Nesse sentido, o diálogo entre história ambiental e migração é estabelecido por esses elementos presentes nos processos em tela: floresta tropical, recursos minerais (minério de ferro e mica), implantação de infraestrutura (eixo rodoferroviário), fronteira agrícola, frente pioneira e correntes migratórias heterogêneas (nacionais e estrangeiras).

\section{Guerra contra o mosquito e a desterritorialização da natureza}

O Vale do Rio Doce foi incorporado ao projeto nacional-desenvolvimentista, no contexto da Segunda Guerra Mundial e do Estado Novo (1937-1945): esperava-se transformá-lo no "Vale do Ruhr" brasileiro (ESPINDOLA, 2013, p. 263). Isso parecia concretizar-se, conforme reportagem especial da revista Cultura Política, de maio de 1944: "O vale do Rio Doce já possui grandes usinas siderúrgicas e desperta para um grande futuro que nos indica que ali se está formando um verdadeiro vale do Ruhr, no Brasil, zona do ferro e do aço". ${ }^{23}$ Os grandes investimentos mi-

\footnotetext{
${ }^{23}$ Reportagem especial de "Cultura Política". Aspecto do Desenvolvimento Social do Brasil. Revista Cultura Política, Rio de Janeiro, v. 4, n. 10, maio, p. 31, 1944.
} 
nero-metalúrgicos estabeleceram seus próprios códigos, por meio de um sistema territorial sobreposto ao território que se constituía a partir da fronteira agrícola.

A implantação da rede rodoferroviária e do complexo mineral e siderúrgico criou um cenário regional novo, que resultou na substituição da frente de ocupação demográfica pela frente pioneira, ao fomentar a formação de grandes fazendas de engorda de gado destinado aos frigoríficos do Rio de Janeiro; multiplicação das serrarias de pequeno e grande porte, crescente urbanização com desenvolvimento dos setores secundários e terciários; intensa exploração dos recursos naturais; grilagem e formação de grandes fazendas; e generalização de conflitos pela posse da terra - nos termos indicados por Martins (1991, p. 67-68; 134).

Nesse contexto, tornou-se prioritário o enfrentamento do quadro nosológico adverso (malária, febre amarela, varíola, leishmaniose, hanseníase, diversos tipos de doenças parasitárias e de outras doenças e patógenos (PINTO, 1944). As endemias não podiam impedir a expansão da siderurgia; a exportação de mica para suprir os aliados em guerra ${ }^{24}$; a reforma da EFVM para transporte de minério em grande escala e implantação da Companhia Vale do Rio Doce (CVRD). ${ }^{25}$ Também não podiam retardar as obras de construção da rodovia Rio-Bahia (BR 116) e de sua ponte sobre o Rio Doce (PINTO, 1944). Duas frentes se formaram para o combate do que se denominou 'endemias rurais': uma de maior proporção ligada aos Acordos de Washington assinados com os EUA e a Grã-Bretanha, em 1942;26 a outra estava ligada ao DNER, que construía a rodovia Rio-Bahia, sendo a primeira no sentido Leste-Oeste e a segunda o sentido Sul-Norte, tendo como eixo a cidade de Governador Valadares.

\footnotetext{
${ }^{24}$ A região do Vale do Rio Doce, com centro na cidade de Governador Valadares, respondeu pela maior parte da extração e beneficiamento da mica para exportação.

${ }^{25}$ Em 1942, o governo de Getúlio Vargas encampou os empreendimentos de Percival Farquhar, nacionalizou a Itabira Iron Ore Company, incorporou a EFVM e criou a Companhia Vale do Rio Doce (VALE S.A.). A VALE recebeu como atribuição a responsabilidade de promover o desenvolvimento da bacia do Rio Doce (MEDEIROS, 1969), mas efetivamente pouco influenciou os rumos do desenvolvimento regional, restringindo-se ao seu próprio sistema territorial baseado na extração, no transporte e na exportação do minério.

${ }^{26}$ Os "Acordos de Washington" selaram a aproximação entre os governos do Brasil e dos EUA, bem como a adesão brasileira ao "esforço de guerra" dos Aliados contra os países do Eixo, durante a II Guerra Mundial (CAMPOS, 2006, p. 35).
} 
A primeira frente foi conduzida pela agência bilateral (Brasil-EUA) Serviço Especial de Saúde Pública - SESP ${ }^{27}$, entre 1943 a 1950: Projeto Rio Doce e Projeto Mica. ${ }^{28} \mathrm{O}$ primeiro atendeu os centros urbanos e as áreas rurais por onde passava a ferrovia; o Projeto Mica penetrou nas áreas circunvizinhas ao Rio Doce, onde se extraia o feldspato que deu nome ao projeto. ${ }^{29}$ O SESP logrou sucesso: erradicação da malária: instalação de serviços de tratamento de água e esgotos nas cidades; formação de pessoal técnico e agentes sanitários e de saúde; campanhas de saúde; educação sanitária e instalação de unidades de saúde. A agência atuou diretamente na mudança de mentalidade e costumes, sobrepondo ao substrato social existente um processo de modernização e uma concepção de mundo técnicocientífica (VILARINO, 2015). Além dos nacionais, estiveram presentes técnicos americanos, tanto no comando da reforma da ferrovia e da implantação da indústria de exportação de mica, como da ação sanitária, conforme foi mencionado por Ladislau Sales, médico do SESP e prefeito de Governador Valadares (1955-1959):

O SESP chegou, chegaram aqueles homens com aqueles chapéus de cortiça, como se vê na África, não é isso? Um chapéu branco, de cortiça, calça branca, etc. Quando viram aquela poeira, passava uma bicicleta levantava poeira, carroça e febre malária, malária, malária, eles não estavam preparados para isso. Então, eles pediram socorro "mande um epidemiologista e mande uma pessoa especializada em doenças tropicais, de países tropicais, porque nós sabemos por alto, mas isso aí a quantidade é muito grande”. Era malária, leishmaniose, que come nariz, esquistossomose, horrível, e não havia tratamento muito eficaz. ${ }^{30}$

Desta vez a entrada dos americanos se deu por outra via, pois os tempos eram muito diferentes daqueles da vinda dos colonos confedera-

\footnotetext{
${ }^{27}$ O SESP foi uma agência de saúde pública criada em 1942, a partir dos Acordos de Washington. O objetivo de "implementar políticas sanitárias em áreas econômica e militarmente estratégicas" atenderia, de um lado, interesses americanos imediatos, relacionados às necessidades de guerra, e de aproximação econômica com o Brasil, e, de outro, respondia aos interesses do governo Vargas de expandir no território brasileiro a presença e a autoridade do Estado (CAMPOS, 2006, p. 173-185).

${ }^{28}$ O SESP, com independência frente aos governos locais, assumiu as ações de combate as endemias, de saneamento e de instalação e manutenção de serviços urbanos básicos nas diversas localidades ao longo do Rio Doce/ferrovia e junto às regiões de extração mineral (VILARINO, 2008).

${ }^{29}$ Numa segunda fase, entre 1948 a 1960, o SESP ampliou sua atuação para outras regiões brasileiras e, em Minas Gerais, para fora do Vale do Rio Doce. Em 1951 o Programa Minas Gerais absorveu o Programa Rio Doce (já não funcionava o Programa Mica).

${ }^{30}$ Entrevista concedida ao Núcleo de História Regional da Univale, em 14 dez. 2001.
} 
dos. Os novos americanos chegaram com recursos poderosos, pois traziam na bagagem o saber científico e a experiência do Canal do Panamá (19041914), fornecendo os meios para o enfrentamento da floresta e dos agentes que até então auxiliavam na sua conservação. A presença de médicos e engenheiros norte-americanos, segundo Soares (2002, p. 110), "colocou os valadarenses em contato com os americanos e sua cultura", estabelecendose "vínculos com os EUA que permitiram a construção, em Valadares, de laços sociais norteadores da opção migratória", que marcariam os valadarenses nas décadas seguintes. ${ }^{31}$

\section{Considerações finais}

As múltiplas e complexas interações que se estabeleceram entre ações humanas e o meio natural envolveram agentes com poder desigual em choque com populações sem poder e vulneráveis, submetidas a dinâmicas exógenas. Os processos sociais desencadeados pela combinação desses múltiplos agentes produziram uma paisagem híbrida no Vale do Rio Doce: de um lado os sistemas territoriais ligados ao complexo minero-metalúrgico e, depois de 1970, ao da celulose-floresta de eucalipto; por outro, a realidade das comunidades locais territorialmente estabelecidas e dos ecossistemas fragilizados ou completamente afetados. A formação histórica do território foi marcada por violentos processos de desterritorialização da natureza e, ao mesmo tempo, das pessoas que perderam suas bases existenciais de sobrevivência comunitária e foram obrigadas a emigrar para outras regiões do Brasil e para o exterior.

Se nas primeiras três décadas do século XX, ainda que de forma limitada, a fronteira tinha se mostrado aberta e receptiva aos agentes da economia "camponesa", o quadro modificou-se quando entraram os interesses capitalistas (BORGES, 1988, p. 209). Na década de 1940, o saneamento foi decisivo para a implantação do sistema territorial do complexo minerometalúrgico e, indiretamente, favoreceu a "frente pioneira": indústria madeireira e pecuária de corte. A combinação da frente pioneira com os interesses capitalistas minero-metalúrgico determinou a rápida redução da área

\footnotetext{
${ }^{31}$ A migração de valadarenses (referência comum a todo emigrante do Vale do Rio Doce) para os EUA, iniciada modestamente na década de 1960, tornou-se um fenômeno explosivo na década de 1980.
} 
florestal (1930-1960), como indica estudo de 1963, encomendado pela CVRD. ${ }^{32} \mathrm{~A}$ área florestal correspondente à depressão periférica do Rio Doce (vale do médio curso do Rio Doce) ficou limitada a 2,5\% da cobertura originária; outras zonas apresentavam variação de 2,5 a $10 \%$, sendo a média geral de 5\%para toda a área de influência da CVRD. ${ }^{33}$

$\mathrm{O}$ ecossistema florestal ficou reduzido a três pequenas áreas: Parque Estadual do Rio Doce, Parque Sete Salões e Reserva Sooretama (pertencente a Vale). Nas seis primeiras décadas do século XX, a região que recebeu imigrantes de diversas origens (nacionais e estrangeiros, entre os quais alemães, italianos, pomeranos, poloneses, libaneses, sírios e outros), tornou-se um centro expulsor (SOARES, 2002). A região do Rio Doce, conforme estudo realizado pelo governo de Minas Gerais, no final da década de 1980, apresentou os maiores índices emigratórios entre as regiões mineiras, além de possuir municípios com indicadores sociais iguais ou piores que os do Jequitinhonha, nacionalmente conhecido pela pobreza (MINAS GERAIS, 1989, p. 102). No campo econômico, esse processo se expressou no fechamento de empresas ou transferência para outras praças; no campo demográfico pelo esvaziamento demográfico; e no campo ambiental foi marcado pelo desaparecimento da floresta e da fauna, redução da oferta hídrica, perda da capacidade de suporte dos solos e generalizados processos erosivos (MINAS GERAIS, 1989). Como disse o velho Maxacali, no final talvez só fique o Mikai-kaka! Assim, podemos afirmar que a combinação dos fenômenos ambientais, econômicos e demográficos fazem da região objeto relevante para os estudos da relação entre história ambiental e migração.

\footnotetext{
${ }^{32}$ CVRD. Perspectivas de desenvolvimento industrial da Região do Rio Doce. III v., São Paulo: SERETE, 1963.

${ }^{33}$ CVRD. Desenvolvimento Agropecuário da Região de Influência da CVRD: estudo básico. São Paulo: Planejamento Agro-Industriais - SEITEC, 1969, p. 248, 251 e 259. A Floresta Atlântica cobria $91 \%$ da área, os Tabuleiros 7,5\% e a vegetação litorânea 1,5\%. As zonas de influência da CVRD apresentavam variação de 2,5 a 10\% de áreas cobertas de remanescentes de matas nativas, sendo a média geral de $5 \%$. O relatório apresentou como as principais causas da redução a demanda por carvão vegetal e lenha, o desmatamento para uso agropecuário e desperdício, principalmente causado pelos incêndios florestais.
} 


\section{Referências e fontes}

ALMEIDA, Ceciliano Abel de. O desbravamento das selvas do Rio Doce. 2 ed. Rio de Janeiro: J. Olímpio, 1978.

BAETA, Alenice Motta; MATTOS, Izabel Missagiade. Habitus, Goiânia, v. 5, n. 1, 2007.

BORGES, Maria Eliza L. Utopia e contra-utopia: movimentos sociais rurais em Minas gerais (1950-1964). Dissertação (Mestrado em História), Universidade Federal de Minas Gerais, Belo Horizonte, 1988.

CAMPOS, André Luiz Vieira de. Politicas Internacionais de Saúde na Era Vargas: o Serviço Especial de Saúde Pública, 1942-1960. Rio de Janeiro: Fiocruz, 2006.

ESPINDOLA, Haruf S. et al. Apropriação de Terras Devolutas e Organização Territorial no Vale do Rio Doce: 1891-1960. In: ESPINDOLA, H. S.; ABREU, J. L. N. (Orgs.). Território, sociedade e modernidade. Governador Valadares: Ed. Univale, 2010, p. 19-58.

ESPINDOLA, Haruf S. et al. Expansão do capital e apropriação de terras florestais no processo de industrialização do Brasil (1891-1960). Cescontexto, Coimbra, v. 1, p. 260-296, 2013.

ESPINDOLA, Haruf S. O Sertão do Rio Doce. Bauru: Edusc, 2005.

ESPINDOLA, Haruf S.; WENDLING, Ivan Jannotti. Elementos biológicos na configuração do território do Rio Doce. Varia História, Belo Horizonte, v. 24, p. 177-197, 2008.

FERREIRA, Manoel Milagres. História e flagrantes de Baixo Guandu. 2. ed. Vitória: Fundação Ceciliano Abel de Almeida, 1985.

FISCHER, Georg. Imigrantes de língua alemã e as visões do paraíso da elite capixaba (1847-1862). Espaço Plural, Marechal Cândido Rondon, n. 19, p. 59-66, $2^{\circ}$ Semestre 2008.

HARTT, Charles Frederick. Geologia e Geografia Física do Brasil. São Paulo: Cia. Ed. Nacional, 1941. (Coleção Brasiliana, 200).

JONES, Judith Mac Knicht. Soldado descansa! Uma epopéia norte-americana sob os céus do Brasil. São Paulo: Jarde, 1967.

KEYES, Julia Louisa. Nossa vida no Brasil: imigração norte-americana no Espírito Santo 1867-1870. Vitória : Arquivo Público do Estado do Espírito Santo, 2013. (O manuscrito original Our life in Brazil: 1867-1870, de 1874, encontra-se no arquivo histórico do estado do Alabama, em Montgomery, nos Estados Unidos.) Disponível em: <https://ape.es.gov.br/Media/ape/PDF/Livros/ LIVRO_NossaVidaNoBrasil_Editado.pdf>. Acesso em: 15 maio 2017. 
KODAMA, Kaori. Os debates pelo fim do tráfico no periódico. O Philantropo (18491852) e a formação do povo: doenças, raça e escravidão. Revista Brasileira de História, São Paulo, v. 28, n. 56, p. 407-430, 2008.

MARTINS, José de Souza. O tempo da fronteira: retorno à controvérsia sobre o tempo histórico da frente de expansão e da frente pioneira. Tempo social: Revista de Sociologia da USP, São Paulo, v. 8, n. 1, p. 25-70, maio 1996.

MARTINS, José de Souza. Expropriação: violência a questão política no campo. 3 ed. Revisada e ampliada. São Paulo: Hucitec, 1991.

MENDONCA, Jaime Araújo. Maxacalis. Rio de Janeiro: M \& M Editores, 1985.

MINAS GERAIS. Economia Mineira - 1989: Diagnóstico e Perspectiva, Belo Horizonte, BDMG, v. 5, 1989.

MIRANDA, Salm. Rio Doce: impressões de uma época. Rio de Janeiro: Biblioteca do Exército, 1949.

NEELEMAN, Gary. A migração confederada ao Brasil: estrelas e barras sob o Cruzeiro do Sul. Porto Alegre: EDIPUCRS, 2016.

PALAZZOLO, Frei Jacinto. Nas Selvas dos Vales do Mucuri e do Rio Doce. São Paulo: Cia. Ed. Nacional, 1973.

PIMENTA, Dermeval José. Aspectos do povoamento do Leste Mineiro. Separata da Revista do IHG MG, n. 14, Imprensa Oficial, 1974.

PINTO, Cesar. Um ano de combate às doenças parasitárias que atacam os rodoviários da estrada Rio-Bahia, 1942-1943. Memórias do Instituto Oswaldo Cruz, Rio de Janeiro, t. 40, fasc. 3, p. 210-352, jun. 1944.

RIOS, José Artur. A Imigração de Confederados Norte-Americanos no Brasil. Boletim Geográfico, Rio de Janeiro, ano VII, n. 81, p. 942-956, 1949.

ROCHA, Levy. Viajantes estrangeiros no Espirito Santo. Brasília: Ed. Brasília, 1971.

ROSA, Léa Brígida Rocha de Alvarenga. Companhia Estrada de Ferro de Vitória a Minas: 1890-1940. Dissertação (Mestrado em História), Universidade de São Paulo, São Paulo, 1976.

SAINT-HILAIRE, Auguste de. Viagem ao Espirito Santo e Rio Doce. Belo Horizonte: Itatiaia; São Paulo: EdUSP, 1974.

SILVEIRA, Álvaro Astolpho da. Memórias Chorographicas. Belo Horizonte: Imprensa Oficial, 1922.

SOARES, Weber. Da Metáfora à Substância: redes sociais, redes migratórias e migração nacional e internacional em Valadares e Ipatinga. Tese (Doutorado), CEDAPLAR/UFMG, Belo Horizonte, 2002.

STEAINS, William John. O Valle do Rio Doce. Revista da Sociedade de Geographia do Rio de Janeiro, Rio de Janeiro, t. 4, n. 3, p. 213-226, 1888. 
STEAINS, William John. An Exploration of the Rio Dôce and its Northern Tributaries (Brazil). Proceedings of the Royal Geographical Society, v. 10, n. 1, p. 61-84, 1888b. STRAUCH, Ney. A Bacia do Rio Doce. Estudo Geográfico, Rio de Janeiro, IBGE/ CNG, 1955.

VILARINO, Maria Terezinha Bretas. Da lata d'agua ao SESP: tensões e constrangimentos de um processo civilizador no Sertão do Rio Doce (1942-1960). Tese (Doutorado em História), Universidade Federal de Minas Gerais, Belo Horizonte, 2015. VILARINO, Maria Terezinha Bretas. Entre lagoas e florestas: atuação do Serviço Especial de Saúde Pública (SESP) no saneamento do médio Rio Doce: 1942-1960. Dissertação (Mestrado em História), Universidade Federal de Minas Gerais, Belo Horizonte, 2008.

WAIBEL, Leo H. As zonas pioneiras do Brasil. Revista Brasileira de Geografia, Rio de Janeiro, ano XVII, n. 4, p. 389-422, out./dez. 1955. 